\title{
Combined TPRx, in situ GISAXS and GIXAS studies of model semiconductor-supported platinum catalysts in the hydrogenation of ethene
}

\author{
Sonja A. Wyrzgol, ${ }^{a}$ Susanne Schäfer, ${ }^{b}$ Sungsik Lee, $\dagger^{c}$ Byeongdu Lee, ${ }^{d}$ \\ Marcel Di Vece, ${ }^{e}$ Xuebing Li, ${ }^{a}$ Sönke Seifert, ${ }^{d}$ Randall E. Winans, ${ }^{d}$ \\ Martin Stutzmann, ${ }^{b}$ Johannes A. Lercher ${ }^{* a}$ and Stefan Vajda $\ddagger^{*} c e f$
}

Received 15th December 2009, Accepted 19th March 2010

First published as an Advance Article on the web 27th April 2010

DOI: $10.1039 / b 926493 k$

The preparation, characterization and catalytic reactivity of a GaN supported Pt catalyst in the hydrogenation of ethene are presented in this feature article, highlighting the use of in situ characterization of the material properties during sample handling and catalysis by combining temperature programmed reaction with in situ grazing incidence small-angle X-ray scattering and X-ray absorption spectroscopy. The catalysts are found to be sintering resistant at elevated temperatures as well as during reduction and hydrogenation reactions. In contrast to Pt particles of approximately $7 \mathrm{~nm}$ diameter, smaller particles of $1.8 \mathrm{~nm}$ in size are found to dynamically adapt their shape and oxidation state to the changes in the reaction environment. These smaller Pt particles also showed an initial deactivation in ethene hydrogenation, which is paralleled by the change in the particle shape. The subtle temperature-dependent X-ray absorbance of the $1.8 \mathrm{~nm}$ sized Pt particles indicates that subtle variations in the electronic structure induced by the state of reduction by electron tunnelling over the Schottky barrier between the Pt particles and the GaN support can be monitored.

\section{Introduction}

Supported and unsupported noble metal particles are used as highly efficient catalysts in a wide range of reactions including catalytic reforming, steam reforming as well emission reduction catalysts to name only three large volume applications. An arsenal of characterization techniques has been developed over the last decade for in situ studying properties of such catalysts during action. Of those techniques, X-ray absorption, X-ray photoelectron spectroscopy, X-ray diffraction and scattering are among the most widely used for supported metal particles. ${ }^{1-8}$ As each specific technique also has limitations, the use of complementary analysis techniques is highly desirable

\footnotetext{
${ }^{a}$ Department of Chemistry and Catalysis Research Center, Technische Universität München, Lichtenbergstr. 4 ,

D-85747 Garching, Germany. E-mail: johannes.lercher@ch.tum.de

${ }^{b}$ Experimental Semiconductor Physics 2, Walter Schottky Institute and Catalysis Research Center, Technische Universität München, Am Coulombwall 3, D-85747 Garching, Germany

${ }^{c}$ Chemical Sciences and Engineering Division, Argonne National Laboratory, 9700 South Cass Avenue, Argonne, IL 60439, USA. E-mail:vajda@anl.gov

${ }^{d}$ X-Ray Sciences Division, Argonne National Laboratory, 9700 South Cass Avenue, Argonne, IL 60439, USA

${ }^{e}$ Department of Chemical Engineering, Yale University, 9 Hillhouse Avenue, New Haven, CT 06520, USA

${ }^{f}$ Center for Nanoscale Materials, Argonne National Laboratory, 9700 South Cass Avenue, Argonne, IL 60439, USA

$\dagger$ Present address at Argonne: X-ray Sciences Division, Argonne National Laboratory, 9700 South Cass Avenue, Argonne, IL 60439, USA.

$\ddagger$ Present address at Argonne: Materials Science Division \& Center for Nanoscale Materials, Argonne National Laboratory, 9700 South Cass
} Avenue, Argonne, IL 60439, USA.
In this work we combine the in situ measurements of smallangle X-ray scattering (GISAXS) and X-ray absorption (GIXAS) in grazing incidence geometry with temperature programmed reaction (TPRx) in a single experiment. The novelty of this experimental approach lies in combining the highly surface-sensitive grazing incidence X-ray scattering and X-ray absorption with temperature-programmed reaction. This combination allows for making a direct correlation between catalyst size and shape, its oxidation state and catalytic performance under reaction conditions in a single experiment. GISAXS provides detailed morphological information about the metal particles, independent of composition or coverage. XANES reveals the electronic state of the particles, while EXAFS provides information about the structure and composition. By using the coordination number obtained from EXAFS analysis, the particle size of well-defined, non oxidized small particles can be estimated. However, for (partially) oxidized or asymmetrical particles GISAXS is the only $\mathrm{X}$-ray technique to elucidate the detailed shape and its change during catalyst treatment. Combining GISAXS and GIXAS and TPRx in one suite sets the direction for the extraction of extremely detailed information about metal particles of nanometric dimensions in a reaction environment.

The small size of catalytically active metal particles (ranging in diameter from less than a nanometre to few nanometres) provides not only a high efficiency with respect to the fraction of usable (accessible) metal atoms; the small size also leads to a high fraction of coordinatively strongly unsaturated sites. Such sites are usually by far more active than the majority of the surface metal atoms. In addition to the size of these 
particles, their shape may determine the arrangements of metal atoms at the surface and both may influence surface states and the overall electronic properties, which all influence activity and selectivity for a particular catalytic reaction. ${ }^{9}$ Different routes have been explored to prepare particles varying in size and geometry. ${ }^{10-12}$ However, even for a given chemical composition, size and shape of the metal particle, the chemical nature of the support as well as its acidity and basicity significantly impacts its stability against sintering and its electronic properties. ${ }^{13}$

In this context, semiconducting supports may influence the electronic structure of nanoparticles via charge transfer and because the semiconductor surface charge density can be altered by thermal, electrical or optical induction, it would add unseen and hitherto unexplored flexibility for small devices. The fact, that a semiconducting material is able to affect a supported metallic species electronically and therefore alters the catalytic reaction, was first observed by Schwab et al. ${ }^{14}$ They found a lower activation energy in the dehydrogenation of formic acid, when the alumina supported $\mathrm{Ni}$ catalyst was doped with $\mathrm{NiO}$ that caused a lower $n$-character of the support. The authors proposed a "synergetic amplification" by the reduction of the Fermi level of metallic layers in contact with a semiconducting oxide and therefore an electron transfer from the metal into the support. This effect leads to a decrease of the activation energy and subsequently to the increase of the catalytic activity. Similar enhancement of catalytic performance was observed for oxide-supported metal catalysts in methanol synthesis, ${ }^{15}$ in the hydrogenation of ethene and $\mathrm{CO},{ }^{16,17}$ as well as in the selective hydrogenation of cyclohexane, cyclopropane and propene. ${ }^{18,19}$

The contact between a metal layer and a semiconductor surface can be described by the Schottky model that assumes a charge separation at the metal-semiconductor interface and a band bending at the interface in the semiconductor. ${ }^{20}$ Doping of the semiconductor causes a charge accumulation or depletion of charge in the metal. In this case, a charge accumulation appeared at the interface in the metal leading to a strong electric field inside the particle and a high instability. The Schottky model can be applied to deposited metal layers as well as to nanometre sized metal particles that were in contact with a semiconducting surface. ${ }^{21}$ The charge separation at the metal semiconductor interface causes an uniform charge distribution over the whole particle surface changing its catalytic behavior. This approach may alter the electronic density of surface atoms by an accumulation or depletion of electrons on the metal particle. The approach may create an accumulation or depletion of electrons on the metal particle potentially changing its catalytic behavior. Thus, conceptually, wide band gap semiconductors, e.g., $\mathrm{TiO}_{2}$ or $\mathrm{GaN}$ may offer the possibility for indirect electronic control of the catalytic action. Due to the contact between metal and semiconductor a Schottky diode can be formed and electrons have to overcome the Schottky barrier for transfer. A transfer of hot electrons from the metal surface into the semiconductor generated by the $\mathrm{CO}$ oxidation was detected by Park and Somorjai using $\mathrm{Pt}-\mathrm{TiO}_{2}$ as well as Pt-GaN diodes. ${ }^{22}$ Furthermore, Pt-GaN heterostructures have been used as chemical sensors for hydrogen with high sensitivity. ${ }^{23}$
This feature article on model catalysts containing Pt nanoparticles that were spin-coated to $n$-GaN aims at understanding and differentiating geometric and electronic effects on the catalytic behavior in a well controlled reaction environment as a first step in this direction.

\section{Experimental}

\subsection{Combined TPRx and in situ GISAXS/GIXAS}

The experiments were performed using a dedicated setup developed at the Sector 12 ID at the Advanced Photon Source of the Argonne National Laboratory.

2.1.1 Grazing incidence small-angle $X$-ray scattering (GISAXS). Grazing incidence small angle X-ray scattering (GISAXS) was used to determine cluster size and shape. This technique has been proved to be very powerful to study particles at surfaces and their transformations under a reactive gas environment at the nanometre as well as the sub-nanometre scale. $^{24-29}$ GISAXS is sensitive to the particles in the surface region, and in addition to particle size it provides particle size distribution, interparticle distance and average aspect ratio of metal particles. ${ }^{24,26-28}$ The GISAXS experiments were performed with $\mathrm{X}$-rays of $11.5 \mathrm{keV}$ energy in a reaction cell of unique design. The cell was sealed with Kapton windows and mounted on a computer controlled goniometer. A $1024 \times$ 1024 pixel two-dimensional MarCCD detector was used for recording the GISAXS images from the sample. GISAXS data were collected as a function of reaction temperature and time. The two-dimensional X-ray images were analyzed by taking cuts in the $q_{x y}$ direction for horizontal information and in the $q_{z}$ direction for vertical information. Scattering vectors $\mathrm{q}$ are calculated from $(4 \pi / \lambda) \sin \theta$ where $\theta$ is the scattering half angle and $\lambda$ is the wavelength of the X-rays. Based on the narrow distribution of the platinum nanoparticles and assuming a spherical shape, the data were analyzed by Guinier analysis, ${ }^{30}$ providing the horizontal and vertical particle radii of gyration $R_{\mathrm{gH}}$ and $R_{\mathrm{gV}}$, respectively The diameter and height of the nanoparticles can be calculated from the radii of gyration as $2.58 \times R_{\mathrm{gH}}$ and $R_{\mathrm{gV}}$, respectively. The aspect ratio of the particles can be calculated as $R_{\mathrm{gH}} / R_{\mathrm{gV}}$.

2.1.2 Grazing incidence X-ray absorption (GIXAS). XAS (XANES/EXAFS) is a powerful technique that is able to monitor changes in oxidation state and local coordination environment of metal nanoparticles during the course of the catalytic reaction. ${ }^{31}$ Unlike conventional approach, GIXAS provides information of near surface region especially when the incident beam is below critical angle. Therefore, GIXAS shows enhanced surface sensitivity which allows monitoring chemical change in samples with a fraction of a monolayer coverage. GIXAS data were collected by a 4-element $\mathrm{Ge}$ fluorescence detector mounted parallel to the sample surface as a function of reaction temperature and time. The collected data were analyzed using the IFEFFIT interactive software package (with ATHENA and ARTEMIS graphical interfaces). ${ }^{32}$

2.1.3 Temperature-programmed reaction (TPRx). During the GISAXS/GIXAS measurements, simultaneous reactivity measurements were also conducted. The reactants used were 
gases at $1 \% \mathrm{C}_{2} \mathrm{H}_{4}$ in $\mathrm{He}$ and $99.7 \% \mathrm{D}_{2}$, and the ratio for $\mathrm{C}_{2} \mathrm{H}_{4}$ and $\mathrm{D}_{2}$ was kept $1: 2$ by preparing the mixture in a remotely controlled gas-mixing unit consisting of calibrated mass flow controllers (Brooks model SLA5850). The reaction cell was operated in a continuous flow mode at $100 \mathrm{kPa}$ pressure and $50 \mathrm{ml} \mathrm{min}{ }^{-1}$ of gas flow. The products were analyzed using a differentially pumped mass-spectrometer (Pfeiffer Vacuum Prisma QMS 200), the turn-over rates (TOR) were calculated using calibrated gas mixtures and the count of deposited Pt nanoparticles. The temperature of the catalyst was controlled using a ceramic heater (Momentive Performance Materials Inc.) allowing heating of samples up to $900 \mathrm{~K}$. The sample temperature was measured with a K-type thermocouple attached to the edge of the heater surface. To achieve thermal equilibrium between the heater and sample during the application of a temperature ramp, a low heating rate $\left(<6 \mathrm{~K} \mathrm{~min}^{-1}\right.$.) was used. The uncertainty in the mass spectrometer signal is estimated to be $\sim 2 \%$ of the ion current, based on standard deviation of 5 to 25 points under steady reaction conditions. With an assumption of a better than $10 \%$ determination of the total metal loading in this study, this error translates into about estimated $10 \%$ uncertainty in the calculation of the total $\mathrm{Pt}$ atom based turn-over rates. The schematic of the combined TPRx/GISAXS/GIXAS experiment is shown in Fig. 1.

\subsection{Sample preparation}

2.2.1 Materials. Chloroplatinic acid solution $(8 \mathrm{wt} \%$ in $\mathrm{H}_{2} \mathrm{O}$ ), poly ( $N$-vinyl-2-pyrrolidone) (PVP40), 1-propanol $(99.7 \%)$ and acetone ( $\geq 99.5 \%)$ were purchased from SigmaAldrich; ethanol (99\%), and 2-propanol ( $\geq 99.5 \%)$ from Merck, nitric acid ( $>65 \%$ in water) and ethylene glycol $(\geq 99.5 \%)$ from Fluka and hydrochloric acid $(32 \%$ in water) from Riedel-de Haën. The chemicals were used without further purification. MOCVD $n$-GaN (donor concentration of Si: $2 \times 10^{18} \mathrm{~cm}^{-3}$ ) was received from Lumilog Group St Gobain Crystals.
2.2.2 Pt nanoparticle preparation. Small platinum particles with an average size of $1.8 \mathrm{~nm}$ were prepared by the alcohol reduction method. ${ }^{11}$ An aqueous solution (bidistilled water $>18.2 \mathrm{M} \Omega \mathrm{cm}, 20 \mathrm{ml}$ ) containing chloroplatinic acid solution $(0.057 \mathrm{mmol})$ and poly $(N$-vinyl-2-pyrrolidone) (PVP) $(2.0 \mathrm{mmol}$ monomer) was stirred at $373 \mathrm{~K}$ for $2 \mathrm{~h}$ before 1-propanol $(130 \mathrm{ml})$ was added as reduction agent. The solvent was evaporated after $48 \mathrm{~h}$ at $373 \mathrm{~K}$. The formed brown residue was then re-dispersed in ethanol $(20 \mathrm{ml})$.

Large platinum particles with an average size of $6.7 \mathrm{~nm}$ were synthesized using the polyol process. ${ }^{33}$ Ethylene glycol solutions of PVP (1.125 mmol monomer, $3 \mathrm{ml})$ and chloroplatinic acid $(0.094 \mathrm{mmol}, 1.5 \mathrm{ml})$ were alternately added to ethylene glycol $(2.5 \mathrm{ml})$ every $30 \mathrm{~s}$ at $473 \mathrm{~K}$. The mixture was refluxed for $5 \mathrm{~min}$ before precipitation with acetone $(21 \mathrm{ml})$ and centrifugation (4000 rpm, $293 \mathrm{~K}, 45 \mathrm{~min}$ ). The residue was re-dispersed in ethanol $(20 \mathrm{ml})$.

\subsubsection{Spin-coating of Pt nanoparticles onto $\boldsymbol{n}$-GaN surfaces.} All substrates were pre-treated with aqua regia $\left(\mathrm{HCl}-\mathrm{HNO}_{3}\right.$ of $3: 1$ ) for $10 \mathrm{~min}$ at $353 \mathrm{~K}$, cleaned in acetone (ultrasonic bath, $10 \mathrm{~min}$ ) and rinsed with 2-propanol. Subsequently after cleaning, $\mathrm{Pt}$ dispersions with defined $\mathrm{Pt}$ concentration in ethanol $\left(2.5 \times 10^{-4} \mathrm{~mol}^{-1} \mathrm{Pt}\right.$ for $1.8 \mathrm{~nm}$ particles and $6.6 \times$ $10^{-4} \mathrm{~mol} \mathrm{l}^{-1} \mathrm{Pt}$ for $6.7 \mathrm{~nm}$ particles) were pipetted $(50 \mu \mathrm{l})$ onto the $n$-GaN surface $(8 \times 8 \mathrm{~mm})$ and spin-coated at $3000 \mathrm{rpm}$ for $60 \mathrm{~s}$. The samples were heated for $5 \mathrm{~min}$ to $363 \mathrm{~K}$ for solvent evaporation. Afterwards, the PVP-capping was removed by oxygen plasma with an oxygen pressure of $1.4 \mathrm{mbar}$ for $5 \mathrm{~min}$ (TePla 100-E, Technics Plasma $\mathrm{GmbH}$ ). To increase the adhesive forces between particles and substrate, the samples were heated at $423 \mathrm{~K}$ for $15 \mathrm{~min}$ in nitrogen atmosphere (100 mbar). For our in situ GISAXS study of particle reduction in deuterium, oxygen plasma treated samples were used. In contrast, for the in situ GISAXS experiments of the deuterium-ethene reaction, the samples were reduced in advance in hydrogen atmosphere $\left(100 \mathrm{ml} \mathrm{min}^{-1}\right)$ for $30 \mathrm{~min}$ at

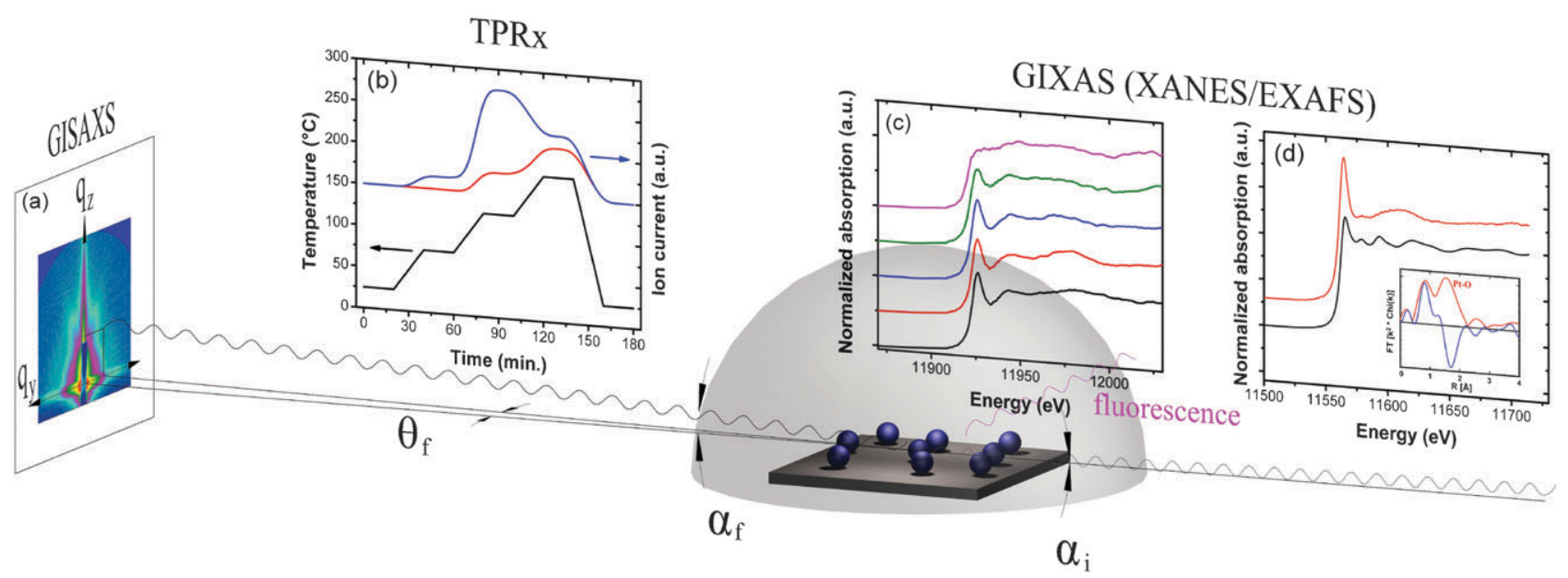

Fig. 1 Schematic of the combined temperature-programmed reaction, grazing-incidence X-ray scattering and X-ray absorption approach. The insets illustrate the capabilities offered by this combination of techniques: (a) two-dimensional in situ GISAXS pattern that allows for the determination of particle size and shape and to study particle stability, (b) monitoring of product evolution with temperature/time, (c) series of XANES spectra collected during in situ reduction of small gold nanoparticles, and (d) example of a quick EXAFS scan on Pt ${ }_{10}$ clusters revealing fully oxidized Pt. 
$373 \mathrm{~K}$ (temperature ramp of $5 \mathrm{~K} \mathrm{~min}^{-1}$ ), followed by flushing

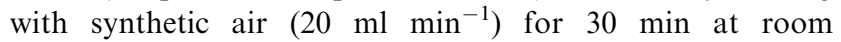
temperature.

\subsubsection{Ex situ sample characterization by transmission} electron microscopy (TEM) and atomic force microscopy (AFM). The average particle sizes of PVP-protected Pt colloids in ethanol were analyzed by TEM (JEOL 2010, $120 \mathrm{kV}$, magnification of 250000$)$. The evaluated particle sizes were averaged from 500 small and 150 large particles, respectively. The errors for the TEM particle size were calculated from the standard deviation of 500 small and 150 large particles, respectively. For the evaluation of the particle distribution on $n$-GaN, AFM images were taken with a Veeco Multimode AFM using a Nanoscope IIIa SPM controller in the tapping mode. AFM probes $\left(204-497 \mathrm{kHz}, 10-130 \mathrm{~N} \mathrm{~m}^{-1}\right.$, tip radius $<7 \mathrm{~nm}$ ) were purchased from Nanosensors. $1 \times 1 \mu \mathrm{m}$ images were recorded with 256 data points per line at a scanning frequency of $1 \mathrm{~Hz}$. The analysis was performed with the WSxM software. ${ }^{34}$ Two images each from the sample center and the edge region were collected for four samples in total. The average particle height and the number of particles per $\mu \mathrm{m}^{2}$ were analyzed. The average particle height was determined by the AFM software for each image resulting in eight images for similar Pt coverage with small and large particles, respectively. The errors in the average particle height were calculated by the standard deviation of the average particle size of the eight images.

\subsection{In situ experiments}

During the TPRx/GISAXS/GIXAS measurements the reactants used were gases at $1 \% \mathrm{C}_{2} \mathrm{H}_{4}$ in $\mathrm{He}$ and $99.7 \% \mathrm{D}_{2}$. Deuterium was chosen based on the following considerations. In the case of $\mathrm{C}_{2} \mathrm{H}_{6}$ and using electron impact ionization, $\mathrm{C}_{2} \mathrm{H}_{4}{ }^{+}$ $(m / z=28)$ is the base peak, at 5 times of the intensity of the $\mathrm{C}_{2} \mathrm{H}_{6}{ }^{+}$parent ion peak $(m / z=30)$, the intensity of the latter potentially not offering a sufficiently intense signal. As far as $m / z=28$ is concerned, the ion signal form traces of nitrogen $(m / z=28)$ present in the reactant gases may interfere and consequently corrupt the data. When using deuterium, the $\mathrm{C}_{2} \mathrm{H}_{2} \mathrm{D}_{2}{ }^{+}, \mathrm{C}_{2} \mathrm{H}_{4} \mathrm{D}^{+}$fragment ions of the product $\mathrm{C}_{2} \mathrm{H}_{4} \mathrm{D}_{2}$ contribute to the $m / z=30$ signal. Another significant advantage of monitoring the $m / z=30$ signal is that there is virtually no background for this $m / z$ in the mass spectrum, unlike in the case of $m / z=32$ which can originate from trace amounts of $\mathrm{O}_{2}$. In the hydrogenation experiments, the ratio of $\mathrm{C}_{2} \mathrm{H}_{4}$ and $\mathrm{D}_{2}$ was kept $1: 2$. In the case of the reduction experiments, an identical concentration of deuterium $(2 \%)$ was used. The in situ reaction cell was operated in a continuous flow mode

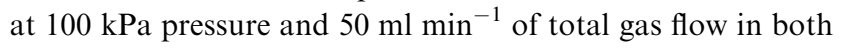
experiments.

\section{Results and discussion}

\subsection{Particle size analysis by TEM, AFM and GISAXS}

An average particle size of $1.8 \pm 0.3 \mathrm{~nm}$ (small) was determined by TEM for particles synthesized by alcohol reduction, while an average particle size of $6.7 \pm 1.1 \mathrm{~nm}$ (large) resulted from the polyol process (Fig. 2). Moreover, particles prepared by the polyol method resulted in cubic or tetragonal particles. In addition to isolated particles, aggregates of particles were observed. The fraction of particle aggregates was $13 \%$ for small and $20 \%$ for large particles.

After the determination of the particle size in dispersion, the particle distribution and coverage on the semiconductor substrate was investigated by AFM (Fig. 3). An average number of 1324 particles per $\mu \mathrm{m}^{2}$ and 20 particles per $\mu \mathrm{m}^{2}$ were calculated for small and large particles, respectively. The coverage was calculated in percentage of a monolayer $(\% \mathrm{ML})$ relative to a $\mathrm{Pt}$ monolayer containing $1.5 \times 10^{15}$ atoms $\mathrm{cm}^{-2}$ for $\mathrm{Pt}(111) .{ }^{35} \mathrm{~A} \mathrm{Pt}$ coverage of $1.6 \% \mathrm{ML}$ was achieved for both particle sizes with a homogeneous distribution on the surface. In contrast to TEM images, the cubic shape of the large particles was not detected by AFM due to limitations in lateral resolution.

From GISAXS data, the average horizontal and vertical radii of gyration $R_{\mathrm{gH}}$ and $R_{\mathrm{gV}}$ were obtained by Guinier plots (i.e., the logarithm of scattering intensity plotted against $q_{y}{ }^{2}$ and $\left.q_{z}{ }^{2}\right) .{ }^{30}$ Note that Guinier analysis does not require an assumption of a particular shape. When assuming a spheroid particle, the lateral diameter and height of the Pt particles were both calculated from the radii of gyration $R_{\mathrm{gH}}$ and $R_{\mathrm{gV}}$ to be $2.58 \times R_{\mathrm{gH}}$ and $2.58 \times R_{\mathrm{gV}}$, respectively. Since both TEM and AFM indicated a distribution of particle sizes and their

(a)

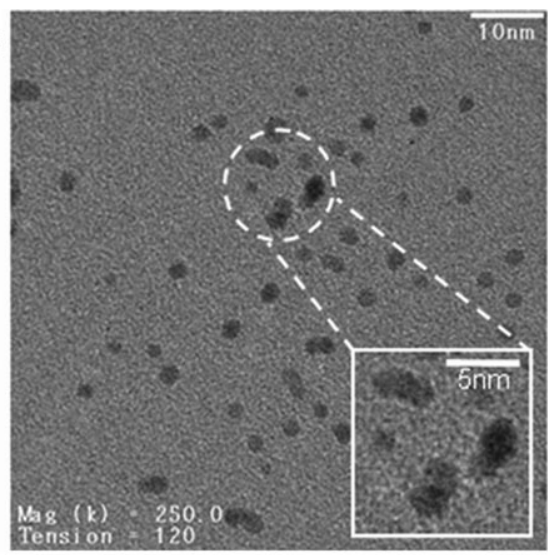

(b)

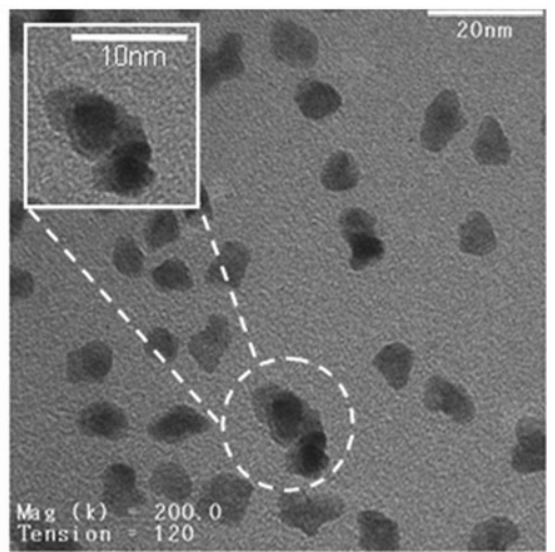

Fig. 2 TEM micrographs of Pt nanoparticles prepared by (a) alcohol reduction with average particle size of $1.8 \pm 0.3 \mathrm{~nm}$ and (b) polyol method with an average particle size of $6.7 \pm 1.1 \mathrm{~nm}$. 

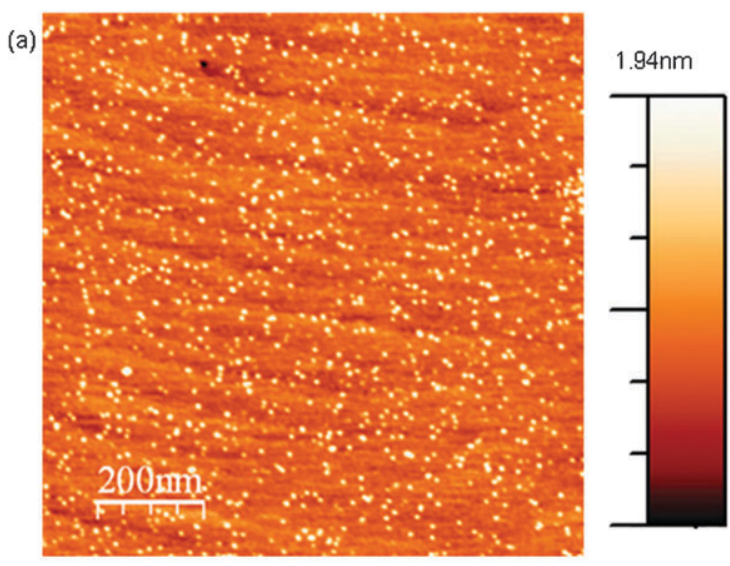

(b)
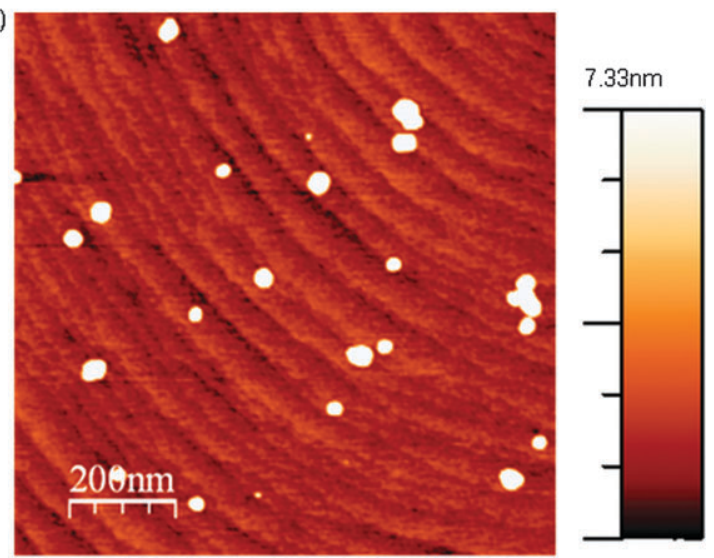

Fig. 3 AFM images of spin-coated Pt nanoparticles on $n$-GaN with particle sizes of (a) $1.8 \pm 0.3 \mathrm{~nm}$ and (b) $6.7 \pm 1.1 \mathrm{~nm}$. The root mean square of blank $n$-GaN was $0.1 \mathrm{~nm}$.

aggregates, the horizontal cut of the GISAXS data was also analyzed using a lognormal distribution of the lateral diameter confirming a range of particle sizes as shown in Fig. 4. The uncertainty in the particle size is estimated to be $\sim \pm 0.1 \mathrm{~nm}$ which is approximately $5 \%$ of the particle size or better. The measurement accuracy in this region could be improved by applying anomalous GISAXS. ${ }^{26}$ Anomalous small angle $\mathrm{X}$-ray scattering refers to an extension of the standard scattering experiments in which the energy of the probing X-rays is tuned near the absorption edge of the interrogated element in the sample. By performing scattering experiments near the characteristic absorption edge of any given atom, it is possible to vary the contrast for scattering of that particular element. This approach solves a major problem with small-angle scattering, namely the lack of a quantitative background subtraction especially in the case of highly diluted samples and very small particles.

The results of TEM, AFM and GISAXS analysis are summarized in Table 1, showing a good agreement.

The stability of spin-coated Pt particles on the semiconductor surface was tested under gas and liquid flux and under mechanical strain. The average particle height and the $\mathrm{Pt}$ coverage were analyzed by AFM and changes such as particle aggregation were not observed. Additionally, the samples were analyzed after the GISAXS/GIXANES and TPRx experiments by AFM, without significant sample modifications.

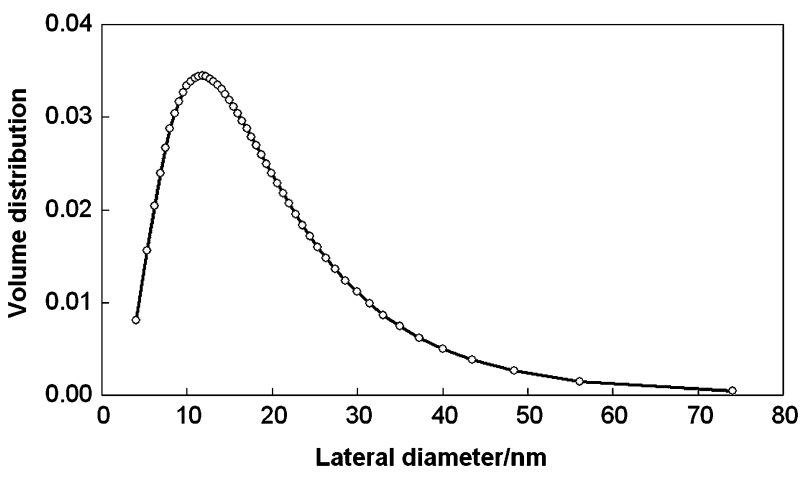

Fig. 4 Result of the fit of the horizontal cut from the GISAXS pattern of the large Pt-particle sample using lognormal distribution.

\subsection{In situ characterization under reduction conditions and elevated temperatures}

In a combined X-ray scattering and X-ray absorption experiment the thermal stability and evolution of the shape of particles was studied together with the change in their oxidation state in the presence of deuterium. The samples were heated in a stepwise fashion in the presence of helium or $\mathrm{D}_{2}$. First, the reaction cell was filled with $\mathrm{He}$ at room temperature and GISAXS and GIXANES were recorded. Then, the temperature was increased to $373 \mathrm{~K}$, the temperature later to be used during the hydrogenation of ethene. At this temperature GISAXS and GIXANES were recorded in He. Next, $\mathrm{D}_{2}$ was introduced for $30 \mathrm{~min}$ and GISAXS and GIXANES were taken at regular time intervals. At the end of the $373 \mathrm{~K}$ step the flow of $\mathrm{D}_{2}$ was replaced by He and GISAXS and GIXANES were recorded again. Subsequently, the temperature was increased in three steps up to $673 \mathrm{~K}$ to monitor shape changes and Pt particle stability. Finally, GISAXS and GIXANES were recorded after cooling back the sample to room temperature. Fig. 5 shows a series of typical two-dimensional GISAXS images recorded during the heat treatment in $\mathrm{He}$ on large $\mathrm{Pt}$ particles. A small change in the GISAXS pattern is observed at $573 \mathrm{~K}$ (Fig. 5c), indicative of an onset in particle shape change to form highly monodisperse objects. ${ }^{28,36}$ Fig. 6 shows horizontal sections of the GISAXS images recorded as a function of temperature in the inert gas environment. The mean particle height and particle width calculated from the vertical and horizontal cuts along with the corresponding aspect ratio are plotted in Fig. 7, for the complete treatment cycle.

The as prepared large Pt particles have a slightly oblate shape (aspect ratio of $\sim 1.2$ ), which does not change after the introduction of deuterium and up to temperatures reaching $473 \mathrm{~K}$ in $\mathrm{He}$ (Fig. 7). At $573 \mathrm{~K}$ the particles become spherical. No change in particle size is observed at temperatures up to $673 \mathrm{~K}$ indicative of highly stable Pt particles. The particles retain their spherical shape after cooling back to room temperature.

The results obtained under identical treatment conditions for the small Pt particles are shown in Fig. 8. At the first, it is obvious that in contrast to the larger Pt particles, the shape of the smaller ones changes dynamically, following the changes in their environment. In $\mathrm{He}$, the oblate particles flatten further, 
Table 1 Pt concentration in ethanol dispersion and corresponding properties as evaluated by TEM, AFM and GISAXS

\begin{tabular}{|c|c|c|c|c|c|c|}
\hline \multirow[b]{2}{*}{$\begin{array}{l}\text { Pt concentration in } \\
\text { ethanol } \times 10^{-4} / \mathrm{mol}^{-1}\end{array}$} & \multirow[b]{2}{*}{$\begin{array}{l}\text { TEM average } \\
\text { size } / \mathrm{nm}\end{array}$} & \multirow[b]{2}{*}{$\begin{array}{l}\text { AFM average } \\
\text { height } / \mathrm{nm}\end{array}$} & \multirow[b]{2}{*}{$\begin{array}{l}\text { GISAXS }^{a} \text { average } \\
\text { height } / \mathrm{nm}\end{array}$} & \multirow[b]{2}{*}{$\begin{array}{l}\text { GISAXS }^{a} \text { average } \\
\text { lateral diameter } / \mathrm{nm}\end{array}$} & \multicolumn{2}{|l|}{ GISAXS $^{b}$} \\
\hline & & & & & $\begin{array}{l}\text { Mean lateral } \\
\text { diameter/nm }\end{array}$ & $\begin{array}{l}\text { FWHM of } \\
\text { distribution } / \mathrm{nm}\end{array}$ \\
\hline 2.5 & $1.8 \pm 0.3$ & $1.8 \pm 0.6$ & $1.5 \pm 0.1$ & $2.0 \pm 0.1$ & - & - \\
\hline 6.6 & $6.7 \pm 1.1$ & $7.9 \pm 1.1$ & $4.5 \pm 0.1$ & $5.3 \pm 0.1$ & $7.8 \pm 0.7$ & 8.7 \\
\hline
\end{tabular}

${ }^{a}$ Determined from Guinier fit. ${ }^{b}$ Determined from the fit of the horizontal cuts using lognormal distribution. In the case of the small particles, the particle size was too small for a lognormal fit. FWHM stands for full width at half maximum.
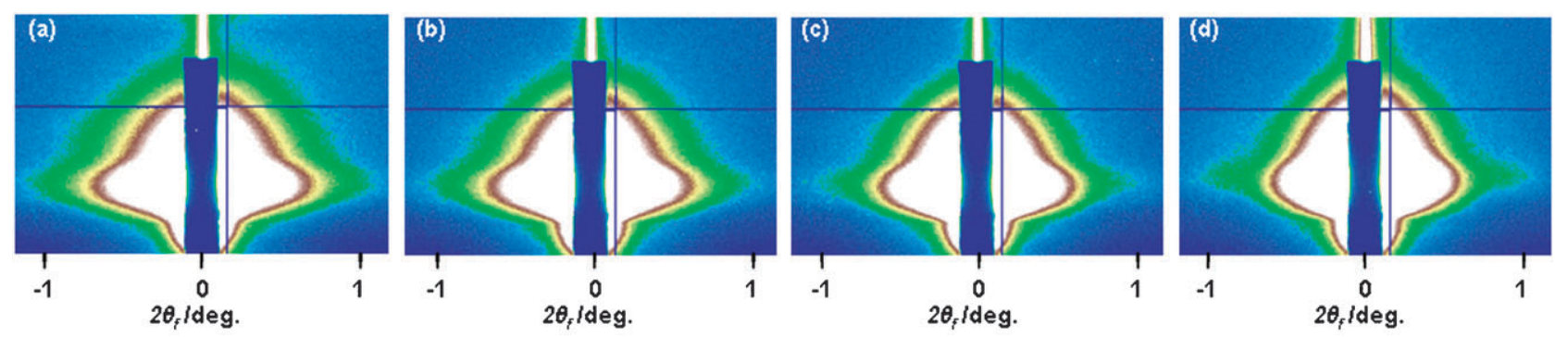

Fig. 5 2D GISAXS patterns of large Pt nanoparticles on $n$-GaN at (a) $298 \mathrm{~K}$, (b) $473 \mathrm{~K}$, (c) $573 \mathrm{~K}$ and (d) $298 \mathrm{~K}$ after temperature cycle in helium.

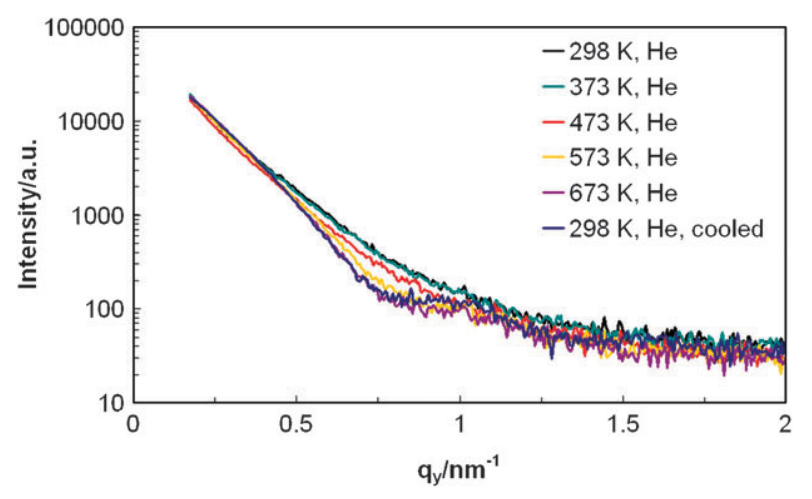

Fig. 6 Background subtracted horizontal cuts of GISAXS data of large Pt nanoparticles on $n-\mathrm{GaN}$ during heat treatment. The distinct feature in the horizontal cuts of GISAXS data at a scattering vector of $1 \mathrm{~nm}^{-1}$ is attributed to highly uniform particles above $573 \mathrm{~K}^{29,61}$

when the temperature is increased to $373 \mathrm{~K}$. A subsequent substantial increase in the aspect ratio is observed upon the introduction of $\mathrm{D}_{2}$ indicating a strong interaction of deuterium with the small Pt particles. After the interruption of the $\mathrm{D}_{2}$ flow, the particles resume a similar shape as observed (before the inlet of $\mathrm{D}_{2}$ ) indicating the reversible response of the particles to changes in the gas composition and temperature. The slight increase in the lateral diameter together with the slight decrease in the height of particles observed at the end of the heating cycle indicates the preservation of the volume of the particles. Thus, if at all, only a very small fraction of $\mathrm{Pt}$ particles underwent sintering during the treatment.

The GIXANES spectra recorded before and after reduction are shown in Fig. 9 and exhibit a decrease in the white line typical for the reduction of Pt particles. ${ }^{37,38}$ The position of the absorption edge of the $\mathrm{Pt}$ particles before reaction is shifted $2.4 \mathrm{eV}$ as compared to the absorption edge position of the $\mathrm{Pt}$ foil, in agreement with a modest oxidation. The slight negative shift of $1.2 \mathrm{eV}$ after reaction suggests the reduction of the Pt particles. It is important to note that the white line intensity of the GIXANES spectrum recorded after reduction does not reach the value of the $\mathrm{Pt}$ metal reference foil spectrum. Recent studies indicate that this may be a genuine
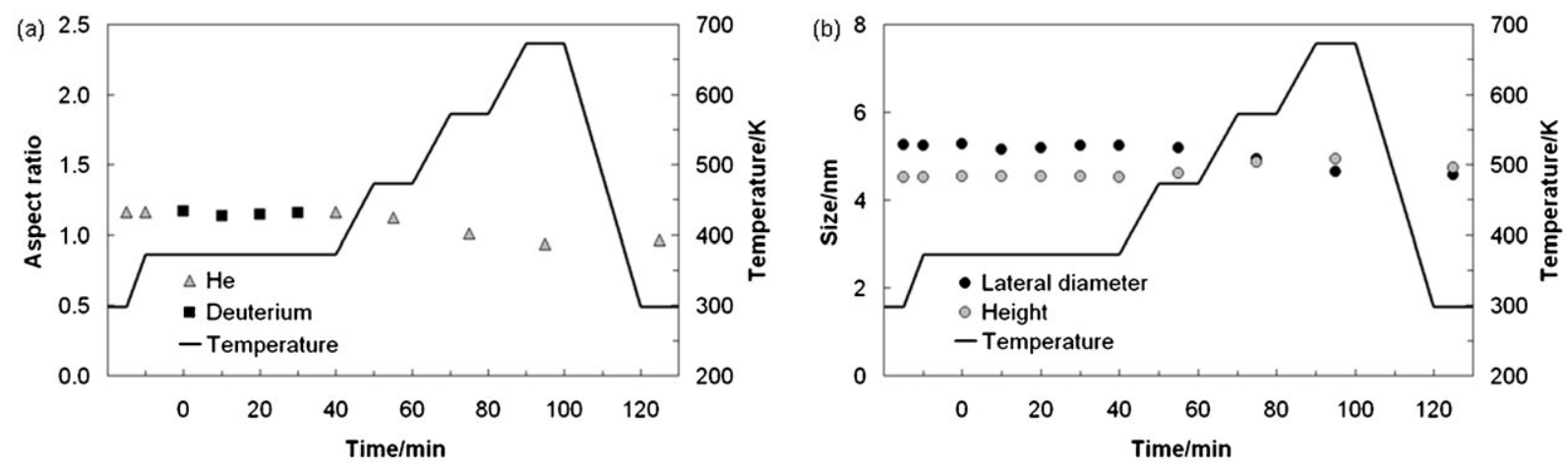

Fig. 7 (a) Aspect ratio of large Pt nanoparticles on $n$-GaN during helium and deuterium treatment and (b) the corresponding average lateral diameter and height of the nanoparticles. The temperature cycle is plotted as a solid line. 

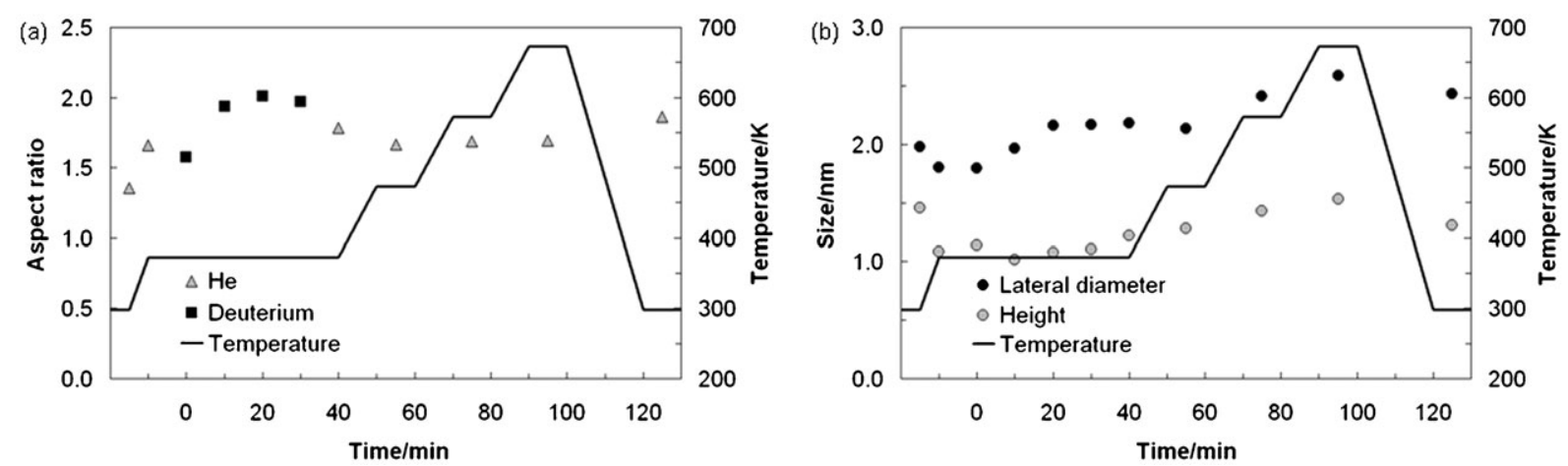

Fig. 8 (a) Aspect ratio of small Pt nanoparticles on $n$-GaN during helium and deuterium treatment and (b) the corresponding lateral diameter and height. The temperature cycle is shown as solid line

effect observed in reduced $\mathrm{Pt}$ nanoclusters attributed to chemisorbed hydrogen on the $\mathrm{Pt}$ surface, where the $\mathrm{Pt}-\mathrm{H}$ bond creates empty antibonding states above the Fermi level that lead to an increase of the white line intensity. ${ }^{39,40}$

Metallic Pt was identified for the large Pt particles before and after deuterium treatment, as indicated by a very similar white line in comparison to the $\mathrm{Pt}$ foil (not shown). The larger Pt particles XANES consequently do not respond to the presence of a reducing atmosphere; the white line intensity remains at the value for the Pt metal foil and the absorption edge does not shift. It should be noted at this point that as compared to the small Pt particles the surface/volume ratio is an order of magnitude smaller. Therefore, the X-ray absorption spectrum is dominated by inner Pt atoms which are metallic. Although similar reduction processes are expected with the oxidized surface of the large Pt particles, the thin oxide shell contributes too little to the total signal to provide a significant difference in the spectra.

The GISAXS and AFM studies demonstrate the high sintering resistance of the GaN-supported Pt particles making the system a suitable model catalyst for reactivity studies. A similar sintering resistance was observed for small oxidesupported $\mathrm{Pt}$ and $\mathrm{Au}$ clusters and $\mathrm{Pt}$ nanoparticles at temperatures reaching $673 \mathrm{~K}$ and higher. ${ }^{41-44}$ The stability against migration is also reflected in the flat shape of the

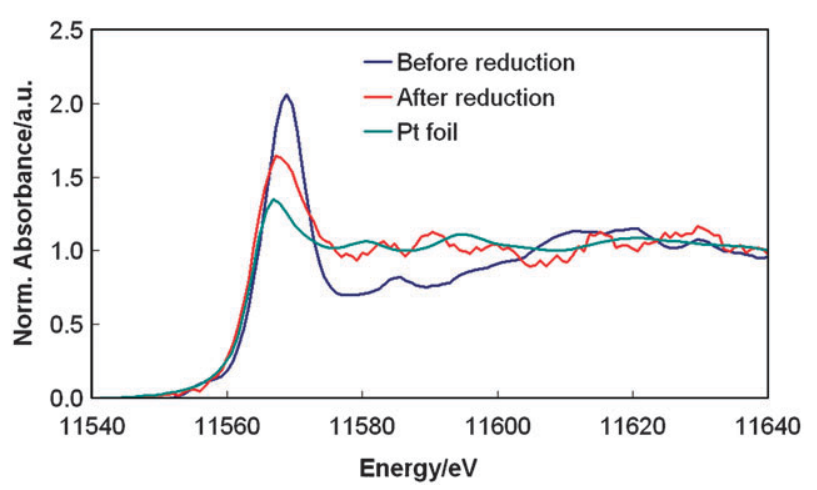

Fig. 9 Normalized $\mathrm{Pt} \mathrm{L}_{3}$ edge spectra of small $\mathrm{Pt}$ nanoparticles on $n$-GaN and Pt foil recorded at $298 \mathrm{~K}$ in helium before and after reduction in deuterium. The GIXANES spectrum measured on Pt foils is included as reference. All recorded GIXANES spectra were analyzed using the XANES dactyloscope software and normalized to unity via average post-edge. particles after preparation indicating a strong metalsemiconductor interaction. The dynamic changes of small Pt nanoparticles exposed to $D_{2}$ is attributed to the change of the surface energy after the adsorption of deuterium and subsequent reduction, which influences wetting. ${ }^{45-48}$ The large particles become spherical above $573 \mathrm{~K}$, which is attributed to Pt atom surface diffusion, because surface melting was not observed below $773 \mathrm{~K}$ for $8 \mathrm{~nm}$ Pt particles. ${ }^{49}$ During reduction of small Pt particles, a reduction of the initially oxidized particles was observed, but a complete reduction of $\mathrm{Pt}$ species was not achieved under given experimental conditions.

In contrast to the small particles, the oxidation state of large particles resembles metallic $\mathrm{Pt}$ and no changes in GIXANES were observed in the presence of $\mathrm{D}_{2}$. Because XANES is a bulk technique and not specifically surface sensitive, it cannot detect small fractions of oxidized metal species at the surface of a particle. ${ }^{31}$ In the case of the small Pt particles, a considerable fraction of the $\mathrm{Pt}$ atoms are surface atoms.

We also observed that the ex situ oxidized samples of small particles had a nearly $30 \%$ larger particle size compared to that of the in situ reduced samples. The larger size is attributed to the presence of a significant oxygen content in the $\mathrm{Pt}$ particles in accordance with the literature ${ }^{50}$ and observed here by GIXANES.

\subsection{Hydrogenation of ethene with deuterium}

For the hydrogenation of ethene over small and large $\mathrm{Pt}$ particles the samples were first reduced ex situ in $\mathrm{H}_{2}$ at $373 \mathrm{~K}$ for $30 \mathrm{~min}$. To study GISAXS during hydrogenation the temperature was increased in $\mathrm{He}$ to $373 \mathrm{~K}$ and the mixture of ethene and $\mathrm{D}_{2}$ was introduced to the reaction cell. The reaction was followed for $30 \mathrm{~min}$ and the catalyst sample was cooled down to room temperature in reactant gas mixture. Then, He was introduced at room temperature. Fig. 10 and 11 show the evolution of the shape for the large and small pre-reduced Pt particles, respectively. The large Pt particles did not change their size or shape. The aspect ratio of the small particles slightly decreased upon the inlet of the reactant mixture returning to the initial shape after the halt of the reactant flow. This is perfectly in line with the dynamic changes of the small particles. GIXANES spectra recorded for the two Pt samples are shown in Fig. 12. The data exhibit a decreasing white line for small particles after the 

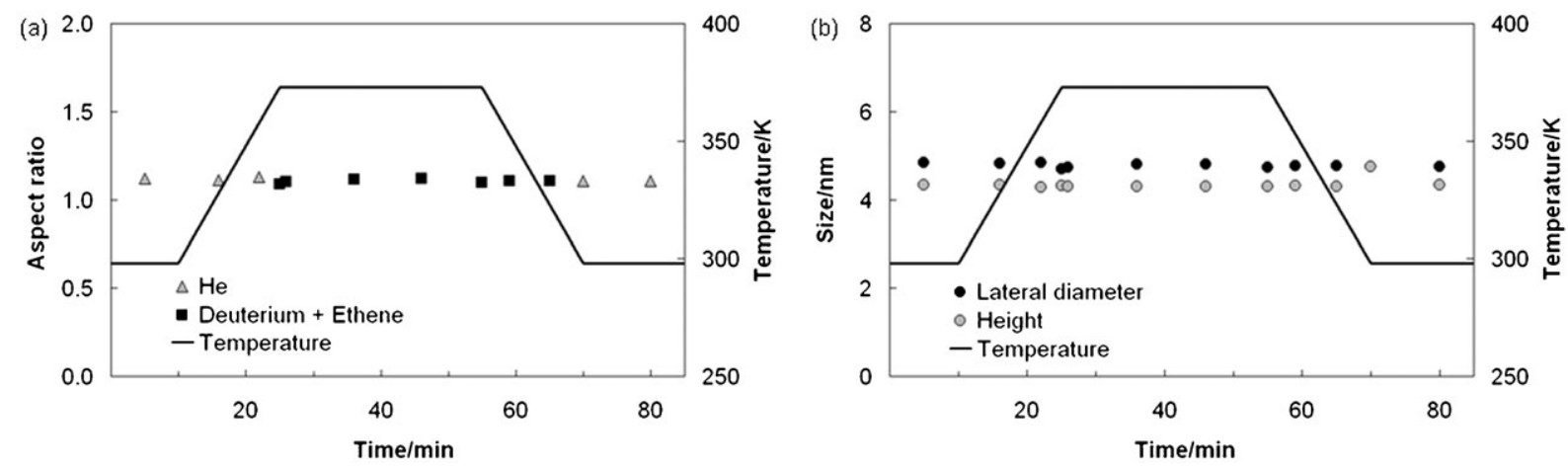

Fig. 10 (a) Aspect ratio of large Pt particles on $n$-GaN during deuterium-ethene reaction and (b) the corresponding lateral diameter and height. The temperature cycle is shown as solid line.

ethene deuteration, which indicates an increase in the degree of reduction of the small Pt particles. ${ }^{37,38}$ Again, the large Pt nanoparticles did not show any changes in their oxidation state before and after reaction. We attribute this to their low surface/volume ratio limiting the sensitivity of the method to pick up variations in the degree of surface reduction.

To investigate the time evolution of the reduction of $\mathrm{Pt}$ particles, the absorbance of small Pt particles at $11.566 \mathrm{keV}$ (absorption peak) was monitored during the reaction of ethene with $\mathrm{D}_{2}$ (Fig. 13). During the temperature ramp from room temperature to $373 \mathrm{~K}$ the height of the white line decreased, which is ascribed to a reduction of the unoccupied states above the Fermi level with temperature. Plausibly, electron tunnelling over the Schottky barrier between the platinum oxide particle and $\mathrm{GaN}$ is increased at elevated temperatures. This leads to a charging of the PtO particle and subsequent reduction of the white line intensity. The absorbance decreased only slightly during $30 \mathrm{~min}$ of reaction at $373 \mathrm{~K}$ and increased again with decreasing temperature, which is tentatively attributed to deuterium adsorption and/or temperature effect of the interactions of the support. ${ }^{51,52}$

The comparison of the time evolution of the Pt white line absorption intensity during ethene hydrogenation at $373 \mathrm{~K}$ on large and small particles shows, as in the case of the pure reduction, a pronounced reduction of the small Pt particles in agreement with their predominantly high surface area (Fig. 14).

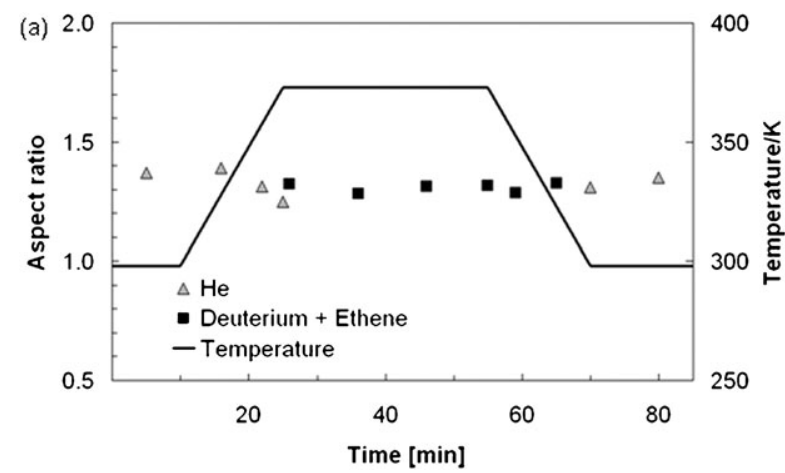

The catalytic activity of small and large GaN-supported Pt particles in ethene hydrogenation with deuterium was investigated by simultaneous TPRx using an on line mass spectrometer. ${ }^{25,27}$ The corresponding TPRx data are shown in Fig. 15.

The turnover rates calculated per total metal atom and per exposed surface atom basis are summarized in Table 2 showing that higher catalytic activity is obtained for small particles on per metal loading basis, as a priori expected solely on their higher surface to volume ratio. However, the activity of this catalyst dropped by about $30 \%$ after the first $10 \mathrm{~min}$ of reaction. The drop in activity coincides with the region where a fine change in particle shape, without indication of sintering takes place. Similar distinct changes in catalytic performance following changes in particle morphology were reported for example for small $\mathrm{Cu}$ and $\mathrm{Ag}$ nanoparticles, ${ }^{25,47}$ however some coking of Pt cannot be fully excluded. A stable ethene conversion of $0.12 \%$ and $0.08 \%$ was determined for small and large Pt particles, respectively, in good accord with the results obtained on $\sim 15 \mathrm{~nm}$ sized Pt particles tested under similar conditions. ${ }^{53}$ The Pt-metal loading-based ethane turnover rates were 22 molecules $\mathrm{Pt}$ atom ${ }^{-1} \mathrm{~s}^{-1}$ (95 molecules $\mathrm{Pt}$ (exposed) $)^{-1} \mathrm{~s}^{-1}$ ) after $4 \mathrm{~min}$ and 15 molecules Pt atom ${ }^{-1} \mathrm{~s}^{-1}$ (63 molecules Pt (exposed) $)^{-1} \mathrm{~s}^{-1}$ ) after 10 min of reaction for small particles. In contrast, large particles had a constant turnover rate of 12 molecules $\mathrm{Pt}$ atoms ${ }^{-1} \mathrm{~s}^{-1}$ (53 molecules $\mathrm{Pt}$ (exposed) $)^{-1} \mathrm{~s}^{-1}$ ) The latter value is comparable with that reported for about $15 \mathrm{~nm}$ large Pt particles. ${ }^{53}$

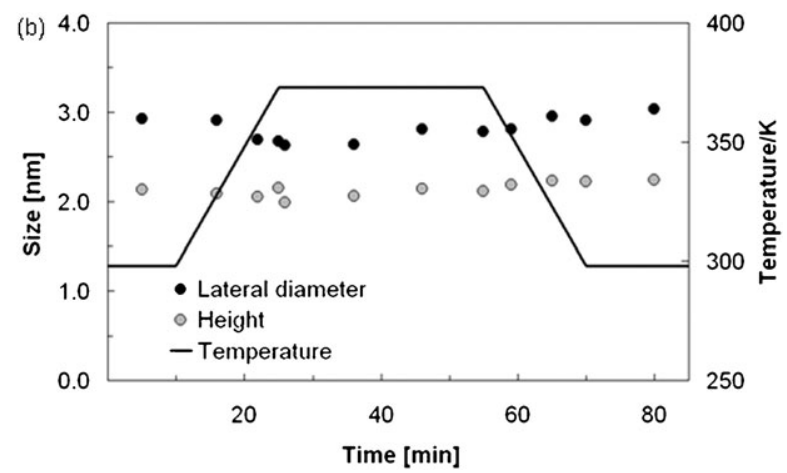

Fig. 11 (a) Aspect ratios of small Pt nanoparticles on $n$-GaN during deuterium-ethene reaction and (b) the corresponding lateral diameter and height. The temperature cycle is plotted as a solid line. Although of an identical aspect ratio to the particles shown in Fig. 8, the Pt particles of this sample are $\sim 30 \%$ larger. 

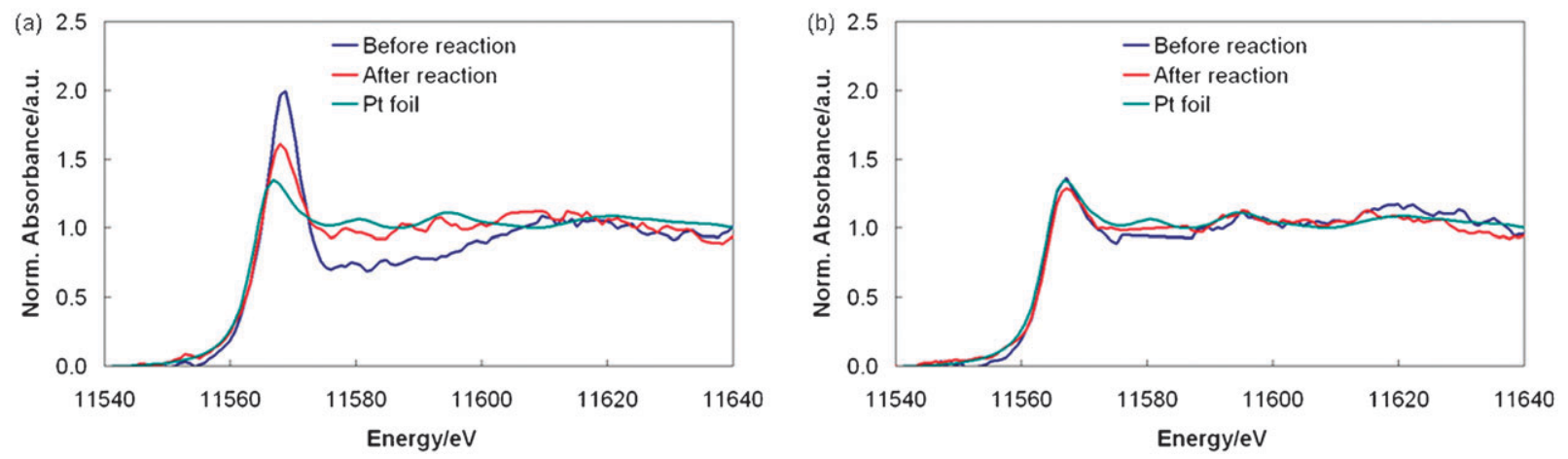

Fig. 12 Normalized $\mathrm{Pt} \mathrm{L}_{3}$ edge spectra of (a) small and (b) large Pt particles on $n$-GaN and Pt foil recorded at $298 \mathrm{~K}$ in helium before and after deuterium-ethene reaction. Additional peaks were detected in XANES spectra for small and large particles in vicinity to the Pt edge due to sample charging, as is known for $\mathrm{N} \mathrm{K}$-edge spectra of GaN. ${ }^{62}$ These peaks were removed in the shown spectra for clarity.

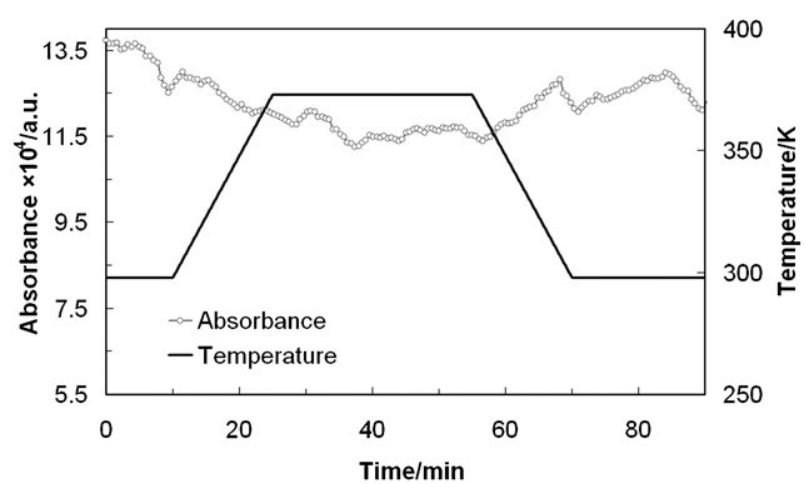

Fig. 13 Absorbance at $11.566 \mathrm{keV}$ monitored for small Pt particles on $n$-GaN during ethene hydrogenation with deuterium.

The GISAXS study during the deuterium-ethene reaction showed that small Pt particles on $n$-GaN changed their shape reversibly, while large particles were not affected. The decreased lateral diameter of small particles in reactant gas atmosphere is attributed to rearrangements of particle facets. The altered surface energy might be caused by adsorbed carbon species that were left on the Pt surface during reaction. ${ }^{54,55}$ Similar dynamic shape transformations were observed from GISAXS during the epoxidation of propene on size-selected silver nanocatalysts by Vajda et al. ${ }^{25}$ It was suggested that propene ligands might alter the surface energy of the particles and the strength of interaction to the support.

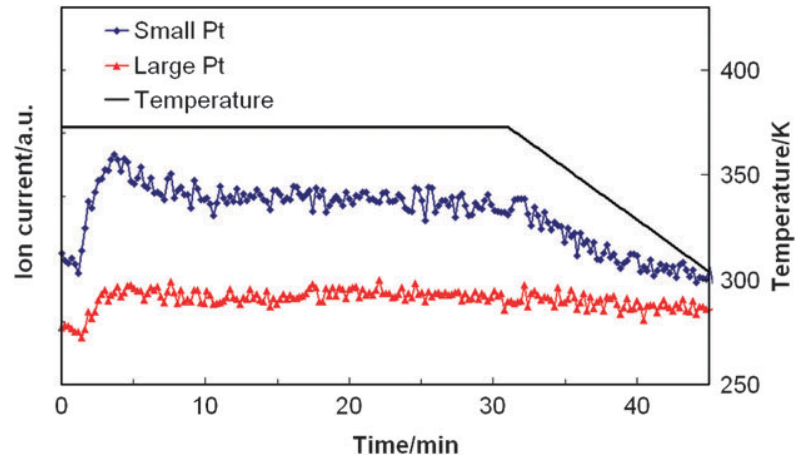

Fig. 15 Ion current of ethane $\left(\mathrm{C}_{2} \mathrm{H}_{4} \mathrm{D}_{2}, m / z=30\right)$ for small and large Pt nanoparticles on $n$-GaN during deuterium-ethene reaction. The temperature is plotted as solid line.

The catalytic activity observed is in good agreement with the activity of a Pt nanoparticle array reported by Grunes et al. ${ }^{53}$ A turnover frequency of 354 molecules $\mathrm{Pt}$ atoms ${ }^{-1} \mathrm{~s}^{-1}$ was found for this Pt particle array prepared by electron beam lithography. It is interesting to note of the small Pt particles deactivated at the beginning of the reaction, but it was concluded that the deactivation was unrelated to particle sintering. Thus, we tentatively attribute the deactivation to changes in faceting of the particles.

The possibility to simultaneously detect GISAXS as well as $\mathrm{X}$-ray fluorescence allows for the measurement of grazing incidence X-ray absorption spectra such as XANES and
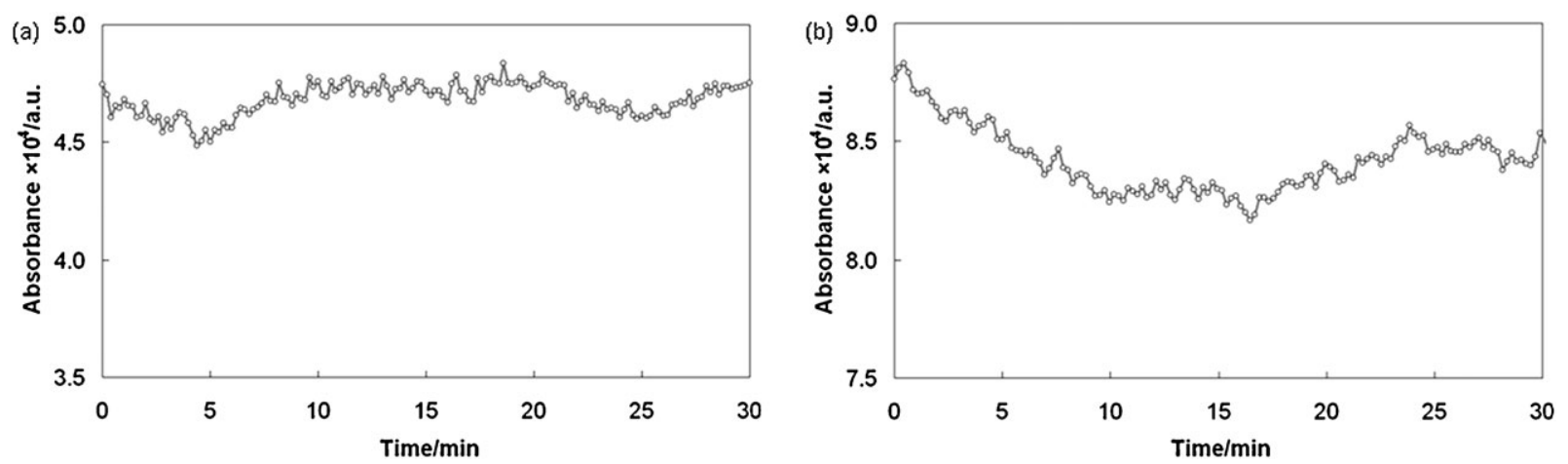

Fig. 14 Absorbance at $11.566 \mathrm{keV}$ monitored for large (a) and small (b) Pt particles on $n$-GaN during deuterium-ethene reaction at $373 \mathrm{~K}$. 
Table 2 Ethene conversion, ethane turnover rate, total and estimated surface Pt atoms for Pt nanoparticles on $n$-GaN

\begin{tabular}{llllll}
\hline & & Total Pt atoms $\times$ & $\begin{array}{l}\text { Turnover rate/ } \\
\text { ethane molecules } \times \\
\text { total Pt atoms }{ }^{-1} \mathrm{~s}^{-1}\end{array}$ & $\begin{array}{l}\text { Surface Pt atoms } \times \\
10^{-12} / \mathrm{mol}^{c}\end{array}$ & $\begin{array}{l}\text { Turnover rate/ } \\
\text { ethane molecules } \times \\
\text { surface Pt atoms }^{-1} \mathrm{~s}^{-1}\end{array}$ \\
\hline Small & $0.18^{a}$ & 2.2 & $20^{-11} / \mathrm{mol}^{\mathrm{c}}$ & 5.2 & $95^{a}$ \\
Large & $0.12^{b}$ & & $15^{b}$ & 3.0 & $63^{b}$ \\
& 0.08 & 1.4 & 12 & 53
\end{tabular}

${ }^{a}$ After 4 min of reaction (peak). ${ }^{b}$ After 10 min of reaction (steady). ${ }^{c}$ Estimate of the number of total atoms in the nanoparticles. A hemispherical particle shape was assumed for small particles and a flat cuboid for large particles, and the volume and surface area calculated from the average height and diameter of particles determined by GISAXS ( $c f$. Table 1). (The area of the particle base inaccessible to reactant molecules was not taken into consideration.) The number of atoms on the surface of the particles was calculated by taking into consideration the $2.77 \AA \mathrm{Pt}-\mathrm{Pt}$ distance in $\mathrm{Pt}(111)$ of a fec structure.

extended X-ray absorption fine structure (EXAFS). ${ }^{56}$ Although EXAFS was not employed in this study, future work on the Pt particle on GaN will involve EXAFS, as this will enable us to exactly determine the amount of oxygen in the platinum nanoparticles. An example of such an experiment performed in the same experimental setup is illustrated in Fig. 1, in which a normalized and background corrected quick EXAFS scan of the oxidized $\mathrm{Pt}_{10}$ nanoclusters on $\mathrm{MgO}$ is presented. Depending on the required data quality, i.e., signal/ noise ratio, the recording time can be varied. In the measurement of Fig. 1 a quick EXAFS is shown with a recording time of only 14 min per scan already providing valuable information about the $\mathrm{Pt}-\mathrm{O}$ bond distance $(0.203 \mathrm{~nm})$ and the coordination number (2.7) which were obtained by estimated fitting of the Fourier transform of the EXAFS in R-space with Arthemis. ${ }^{32}$

\section{Conclusion}

In the presented study, Pt nanoparticles with two different sizes of $1.8 \mathrm{~nm}$ and $6.7 \mathrm{~nm}$ supported on $n$-GaN surfaces were studied by combined in situ GISAXS, GIXANES and TPRx during reduction and deuterium-ethene reaction. Particle size analysis was complemented by ex situ methods such as TEM and AFM. The model catalysts resisted sintering during reduction and hydrogenation reaction at $373 \mathrm{~K}$ as well as at stability test with temperatures reaching $673 \mathrm{~K}$. However, the deuterium and deuterium-ethene atmosphere at $373 \mathrm{~K}$ had a significant impact on the shape of the smaller $\mathrm{Pt}$ particles, which dynamically responded to changes in their environment. Small $\mathrm{Pt}$ particles as well as large Pt particles showed catalytic activity in deuteration of ethene with turnover rates comparable to literature values. ${ }^{53}$ The small particles exhibited a deactivation period in the first $10 \mathrm{~min}$ of reaction that was not related to particle sintering or particle shape changes, but most likely to changes in the morphology of the particles. ${ }^{47}$ The decrease in the white line intensity with increasing temperature during the reaction on small particles reflects an increase in the electron density of the particles. This suggest a charge transfer that occurred by thermal induction of the support material. The control of this energy input by e.g. illumination in the semiconductor band gap region could help to alter the electron density on the metal particle and to realize catalysis on demand.
The research on small metal particles for catalysis has been of broad interest among others due to the large fraction of surface atoms that drive surface reactions. But for structure sensitive reactions such as isomerization, hydrogenolysis, ${ }^{57}$ both the size and shape of the Pt particles are crucial for their activity and selectivity. Our study revealed dynamic changes in the particle shape of small particles in deuterium and deuteriumethene gas mixtures that may be responsible for the varying catalytic performance. This dynamic structural/morphological change of small nanoparticles under reaction conditions should be considered not only in studies of structure sensitive reactions, but also in reactions in which adsorption of one of the reactants can cause a dynamic structural disorder of the surface and/or affect the morphology of the whole particle. ${ }^{58-60,24,25,46,47}$ The change in particle shape, along with the potential restructuring of the catalyst-support interface, may also alter the electronic structure of small particle and its interaction (including charge transfer) with the support during the course of the catalytic reaction. On the other hand, size- and shape-selective synthesis of large particles also could help for a better understanding of structure sensitive reactions, because the shape of the large particles was not affected by deuterium and the deuterium-ethene mixture.

In brief, the combination of surface-sensitive in situ GISAXS and GIXANES with TPRx proved to be a powerful method to study the effect of particle size, shape and oxidation state of model catalyst as illustrated on the example of semiconductor-supported $\mathrm{Pt}$ catalysts under realistic reaction conditions.

\section{Acknowledgements}

The work at the Technische Universität München (TUM) was supported by Deutsche Forschungsgemeinschaft (DFG) through the TUM International Graduate School of Science and Engineering (IGSSE). TEM and AFM analysis was performed at the Laboratory of Electron microscopy, Department of Chemistry, Technische Universität München. The work at the Argonne National Laboratory was supported by the US Department of Energy, BES-Chemical Sciences and BES-Scientific User Facilities under Contract DE-AC-0206CH11357 with UChicago Argonne, LLC, Operator of Argonne National Laboratory. MDV and SV gratefully acknowledge the support by the Air Force Office of Scientific Research. 


\section{References}

1 A. Stierle and A. M. Molenbroek, MRS Bull., 2007, 32, 1001-1005.

2 P. L. J. Gunter, J. W. Niemantsverdriet, F. H. Ribeiro and G. A. Somorjai, Catal. Rev. Sci. Eng., 1997, 39, 77-168.

3 S. E. Deutsch, J. T. Miller, K. Tomishige, Y. Iwasawa, W. A. Weber and B. C. Gates, J. Phys. Chem., 1996, 100, 13408-13415.

4 E. Bus, R. Prins and J. A. van Bokhoven, Phys. Chem. Chem. Phys., 2007, 9, 3312-3320.

$5 \mathrm{M}$. G. O'Brien, A. M. Beale, S. D. M. Jacques and B. M. Weckhuysen, Top. Catal., 2009, 52, 1400-1409.

6 J. A. van Bokhoven, C. Louis, J. T Miller, M. Tromp, O. V. Safonova and P. Glatzel, Angew. Chem., Int. Ed., 2006, 45, 4651-4654.

7 V. V. Kaichev, I. P. Prosvirin, V. I. Bukhtiyarov, H. Unterhalt, G. Rupprechter and H. J. Freund, J. Phys. Chem. B, 2003, 107, $3522-3527$.

8 B. C. Gates, H. Knoezinger and F. Jentoft, Advances in Catalysis, Academic Press, 2009, vol. 52.

9 G. C. Bond, Chem. Soc. Rev., 1991, 20, 441-475.

10 M. M. Koebel, L. C. Jones and G. A. Somorjai, J. Nanopart. Res., 2008, 10, 1063-1069.

11 G. W. Busser, J. G. van Ommen and J. A. Lercher, J. Phys. Chem. B, 1999, 103, 1651-1659.

12 T. Teranishi, M. Hosoe, T. Tanaka and M. Miyake, J. Phys. Chem. B, 1999, 103, 3818-3827.

13 A. Y. Stakheev and L. M. Kustov, Appl. Catal., A, 1999, 188, 3-35.

14 G. M. Schwab, J. Block, W. Muller and D. Schultze, Naturwissenschaften, 1957, 44, 582-582.

15 J. C. Frost, Nature, 1988, 334, 577-580.

16 G. M. Schwab and G. Mutzbauer, Naturwissenschaften, 1959, 46, 13-14.

17 F. Solymosi, I. Tombacz and M. Kocsis, J. Catal., 1982, 75, 78-93.

18 W. Langenbeck, D. Nehring and H. Dreyer, Z. Anorg. Allg. Chem., 1960, 304, 37-47.

19 W. Langenbeck, D. Nehring, H. Dreyer and H. Fuhrmann, Z. Anorg. Allg. Chem., 1962, 314, 167-178.

20 W. Schottky, Z. Angew. Phys., 1939, 113, 367.

21 V. P. Zhdanov, Surf. Sci., 2002, 512, L331-L334.

22 J. Y. Park and G. A. Somorjai, J. Vac. Sci. Technol., B, 2006, 24, 1967-1971.

23 M. Ali, V. Cimalla, V. Lebedev, H. Romanus, V. Tilak, D. Merfeld, P. Sandvik and O. Ambacher, Sens. Actuators, B, 2006, 113, 797-804.

24 Y. Lei, F. Mehmood, S. Lee, J. P. Greeley, B. Lee, S. Seifert, R. E. Winans, J. W. Elam, R. J. Meyer, P. C. Redfern, D. Teschner, R. Schlögl, M. J. Pellin, L. A. Curtiss and S. Vajda, Science, 2010, 328, 224-229.

25 S. Vajda, S. Lee, K. Sell, I. Barke, A. Kleibert, V. von Oeynhausen, K.-H. Meiwes-Broer, A. F. Rodriguez, J. W. Elam, M. M. Pellin, B. Lee, S. Seifert and R. E. Winans, J. Chem. Phys., 2009, 131, 121104.

26 B. Lee, S. Seifert, S. J. Riley, G. Tikhonov, N. A. Tomczyk, S. Vajda and R. E. Winans, J. Chem. Phys., 2005, 123, 74701.

27 S. Lee, L. M. Molina, M. J. Lopez, J. A. Alonso, B. Hammer, B. Lee, S. Seifert, R. E. Winans, J. W. Elam, M. J. Pellin and S. Vajda, Angew. Chem., Int. Ed., 2009, 48, 1467-1471.

28 G. Renaud, R. Lazzari, C. Revenant, A. Barbier, M. Noblet, O. Ulrich, F. Leroy, J. Jupille, Y. Borensztein, C. R. Henry, J. P. Deville, F. Scheurer, J. Mane-Mane and O. Fruchart, Science, 2003, 300, 1416-1419.

29 J. R. Levine, L. B. Cohen, Y. W. Chung and P. Georgopoulos, J. Appl. Crystallogr., 1989, 22, 528-532.

30 A. Guinier, G. Fournet, C. B. Walker and K. 1. Yudowitch, Small Angle Scattering of X-Rays, Wiley, 1955.

31 J. E. Penner-Hahn, Coord. Chem. Rev., 1999, 190-192, 1101-1123.

32 B. Ravel and M. Newville, J. Synchrotron Radiat., 2005, 12, $537-541$.
33 R. M. Rioux, H. Song, J. D. Hoefelmeyer, P. Yang and G. A. Somorjai, J. Phys. Chem. B, 2005, 109, 2192-2202.

34 I. Horcas, R. Fernandez, J. M. Gomez-Rodriguez, J. Colchero, J. Gomez-Herrero and A. M. Baro, Rev. Sci. Instrum., 2007, 78, 013705.

35 Y. Y. Yeo, L. Vattuone and D. A. King, J. Chem. Phys., 1997, 106, 392-401.

36 C. Revenant, F. Leroy, R. Lazzari, G. Renaud and C. R. Henry, Phys. Rev. B: Condens. Matter Mater. Phys., 2004, 69, $035411-035426$

37 I. E. Beck, V. V. Kriventsov, D. P. Ivanov, V. I. Zaikovsky and V. I. Bukhtiyarov, Nucl. Instrum. Methods Phys. Res., Sect. A, 2009, 603, 108-110.

38 F. W. Lytle, P. S. P. Wei, R. B. Greegor, G. H. Via and J. H. Sinfelt, J. Chem. Phys., 1979, 70, 4849-4855.

39 J. Bartolome, F. Bartolome, L. M. Garcia, E. Roduner, Y. Akdogan, F. Wilhelm and A. Rogalev, Phys. Rev. B: Condens. Matter Mater. Phys., 2009, 80, 014404.

40 D. E. Ramaker, B. L. Mojet, M. T. G. Oostenbrink, J. T. Miller and D. C. Koningsberger, Phys. Chem. Chem. Phys., 1999, 1, 2293-2302.

41 R. E. Winans, S. Vajda, B. Lee, S. J. Riley, S. Seifert, G. Y. Tikhonov and N. A. Tomczyk, J. Phys. Chem. B, 2004, 108, 18105-18107.

42 S. Vajda, R. E. Winans, J. W. Elam, B. D. Lee, M. J. Pellin, S. Seifert, G. Y. Tikhonov and N. A. Tomczyk, Top. Catal., 2006, 39, 161-166.

43 R. E. Winans, S. Vajda, G. E. Ballentine, J. W. Elam, B. D. Lee, M. J. Pelline, S. Seifert, G. Y. Tikhonov and N. A. Tomczyk, Top. Catal., 2006, 39, 145-149.

44 S. Vajda, M. J. Pellin, J. P. Greeley, C. L. Marshall, L. A. Curtiss, G. A. Ballentine, J. W. Elam, S. Catillon-Mucherie, P. C. Redfern, F. Mehmood and P. Zapol, Nat. Mater., 2009, 8, 213-216.

45 T. Wang, C. Lee and L. D. Schmidt, Surf. Sci., 1985, 163, 181-197.

46 P. Nolte, A. Stierle, N. Y. Jin-Phillipp, N. Kasper, T. U. Schulli and H. Dosch, Science, 2008, 321, 1654-1658.

47 P. L. Hansen, J. B. Wagner, S. Helveg, J. R. Rostrup-Nielsen, B. S. Clausen and H. Topsoe, Science, 2002, 295, 2053-2055.

48 C. R. Henry, Prog. Surf. Sci., 2005, 80, 92-116.

49 Z. L. Wang, J. M. Petroski, T. C. Green and M. A. El-Sayed, J. Phys. Chem. B, 1998, 102, 6145-6151.

50 A. P. Markusse, B. F. M. Kuster, D. C. Koningsberger and G. B. Marin, Catal. Lett., 1998, 55, 141-145.

51 F. W. Lytle, R. B. Greegor, E. C. Marques, D. R. Sandstrom, G. H. Via and J. H. Sinfelt, J. Catal., 1985, 95, 546-557.

52 M. G. Samant and M. Boudart, J. Phys. Chem., 1991, 95, 4070-4074.

53 J. Grunes, J. Zhu, E. A. Anderson and G. A. Somorjai, J. Phys. Chem. B, 2002, 106, 11463-11468.

54 P. S. Cremer and G. A. Somorjai, J. Chem. Soc., Faraday Trans., 1995, 91, 3671-3677.

55 P. S. Cremer, X. C. Su, Y. R. Shen and G. A. Somorjai, Catal. Lett., 1996, 40, 143-145.

56 D. C. Koningsberger, B. L. Mojet, G. E. van Dorssen and D. E. Ramaker, Top. Catal., 2000, 10, 143-155.

57 G. A. Somorjai, Abstr. Pap. Am. Chem. Soc., 1985, 189, 79-INDE.

58 F. Tao, S. Dag, L. W. Wang, Z. Liu, D. R. Butcher, H. Bluhm, M. Salmeron and G. A. Somorjai, Science, 2010, 327, $850-853$.

59 M. A. Newton, C. Belver-Coldeira, A. Martinez-Arias and M. Fernandez-Garcia, Nat. Mater., 2007, 6, 528-532.

60 G. Renaud, R. Lazzari and F. Leroy, Surf. Sci. Rep., 2009, 64, 255-380.

61 M. Harada, K. Saijo, N. Sakamoto and H. Einaga, Colloids Surf., A, 2009, 345, 41-50.

62 M. Katsikini, T. D. Moustakas and E. C. Paloura, J. Synchrotron Radiat., 1999, 6, 555-557. 